\title{
ALTERAÇÕES DE ALGUNS ATRIBUTOS FÍSICOS E DAS FRAÇÕES HÚMICAS DE UM NITOSSOLO VERMELHO NA SUCESSÃO MILHETO-SOJA EM SISTEMA PLANTIO DIRETO(1)
}

\author{
Sandro Roberto Brancalião ${ }^{(2)} \&$ Maria Helena Moraes $^{(3)}$
}

\begin{abstract}
RESUMO
No Estado de São Paulo, restrições do regime de chuvas no período de outonoinverno e temperaturas elevadas limitam a produção e a manutenção de cobertura no solo, tornando importante estudar alternativas para a implantação eficaz do Sistema Plantio Direto nesse Estado, especialmente para produção de fitomassa e manejo adequado para maior persistência da palha, em quantidade suficiente para melhoria da qualidade física e da matéria orgânica do solo. O experimento, conduzido em Nitossolo Vermelho distroférrico, na Fazenda Experimental LageadoFCA-UNESP-Botucatu, teve por objetivo estudar no sistema plantio direto as prováveis alterações de alguns atributos físicos e das frações húmicas do solo com a utilização do milheto, verificando sua resposta, em três épocas de semeadura e sob cinco manejos dos resíduos, após cinco anos de estabelecida essa sucessão. 0 delineamento experimental foi o de blocos casualizados, com esquema de parcelas subdivididas, com quatro repetições. As parcelas foram representadas por três épocas de semeadura da cultura do milheto: época $1\left(E_{1}\right)$, época $2\left(E_{2}\right)$ e época 3 $\left(E_{3}\right)$. As subparcelas foram representadas por manejos da ceifa da fitomassa, sendo: manejo $1\left(M_{1}\right)$ - ceifa a cada florescimento e retirada da fitomassa; manejo $2\left(M_{2}\right)$ ceifa a cada florescimento e permanência da fitomassa; manejo $3\left(\mathbf{M}_{3}\right)$ - ceifa apenas no primeiro florescimento e retirada da fitomassa; manejo $4\left(M_{4}\right)$ - ceifa apenas no primeiro florescimento e permanência da fitomassa; e manejo $5\left(M_{5}\right)$ - livre crescimento. Foram coletadas amostras de solo com estrutura indeformada para realização das análises físicas, para as quais as profundidades amostradas foram: 0-0,05, 0,05-0,10 e 0,10-0,20 m. Para fracionamento químico da matéria orgânica, as profundidades foram de 0-0,05 e 0,05-0,10 m. Em relação às culturas, avaliou-se a produtividade da soja, e para o milheto, a quantidade de matéria seca produzida
\end{abstract}

\footnotetext{
(1) Parte da Tese de Doutorado do primeiro autor apresentada na Faculdade de Ciências Agronômicas, Universidade Estadual Paulista - FCA/UNESP. XXX CBCS, RECIFE (PE). Recebido para publicação em maio de 2006 e aprovado em outubro de 2007.

(2) Pesquisador Científico, Instituto Agronômico - IAC. Caixa Postal 28, CEP 13020-902 Campinas (SP). E-mail: brancaliao@iac.sp.gov.br

${ }^{(3)}$ Professor Adjunto do Departamento de Recursos Naturais, Ciência do Solo da Faculdade de Ciências Agronômicas, Universidade Estadual Paulista - FCA/UNESP. Fazenda Experimental Lageado s/n, Caixa Postal 237, CEP 18603-970 Botucatu (SP). E-mail: mhmoraes@fca.unesp.br
} 
pela parte aérea e a percentagem de fitomassa em cobertura deixada sobre o solo. A produtividade de matéria seca do milheto decresceu na ordem $E_{1}>E_{2}>E_{3}$. $A$ densidade do solo, a macroporosidade, a microporosidade e a porosidade total variaram com a época de semeadura do milheto. A adição contínua de fitomassa com ceifa a cada florescimento e permanência da cobertura proporcionou maior incremento nas frações menos estáveis da matéria orgânica (ácido húmico e ácido fúlvico). Recomenda-se, diante das condições edafoclimáticas estudadas, a semeadura do milheto na segunda e terceira épocas com ceifa apenas no primeiro florescimento, sempre se utilizando da permanência da fitomassa, para obter melhor cobertura, qualidade física do solo (menor densidade do solo, maior porosidade total) e maior produtividade para soja.

Termos de indexação: densidade do solo, porosidade total, semeadura direta, Pennisetum glaucum, substâncias húmicas.

\title{
SUMMARY: CHANGES IN SOME PHYSICAL PROPERTIES AND IN HUMIC FRACTIONS OF A NITOSOL CROPPED WITH A MILLET - SOYBEAN SUCCESSION UNDER NO-TILLAGE
}

\begin{abstract}
In São Paulo State, the autumn - winter seasons rainfall distribution restriction as well as high temperatures constitute a serious limitation for soil surface covering and crop production. For this reason it is very important to study alternatives for the no tillage system establishment in that State, specially for biomass production and for adequate management for better mulching in amount enough to improve soil physical quality and organic matter content. This study was carried out at the Lageado Experimental Station (UNESP - Botucatu, Brazil) from October 2001 through April 2004. The experiment consisted of a millet - soybean succession, under no-tillage, in which three millet sowing dates and five millet biomass management systems were tested. The aim was to evaluate alterations in some physical properties and in humic fractions of a Nitosol (Alfisol). The experiment was arranged in randomized blocks, in a split-plot scheme with four replications. The plots were represented by the sowing dates $\left(S_{1}, S_{2}, S_{3}\right)$ and the subplots as biomass harvest systems ( $1\left(\mathrm{H}_{1}\right)$ - cut at each flowering and removal of biomass; $2\left(\mathrm{H}_{2}\right)$ - cut at flowering and biomass maintenance; $3\left(\mathrm{H}_{3}\right)$ - harvest only at first flowering and removal of biomass; $H_{4}$ - harvest only at first flowering and biomass maintenance, and $H_{5}-$ free growth, with no harvest. Undisturbed soil samples were collected from four layers $(0-0.05$, $0.05-0.10$ and $0.10-0.20 \mathrm{~m})$ to evaluate the physical properties. To quantify the humic fractions (C-HA, $C$-FA and $C$ - $H U$ ), only the layers $0-0.05$ and $0.05-0.10 \mathrm{~m}$ were analyzed. Pearl millet dry matter yield followed the order $S_{1}>S_{2}>S_{3}$. Bulk density, macroporosity, microporosity and total porosity varied according to the millet sowing date. The continuous increment of biomass with a cut at each flowering and maintenance of the soil cover resulted in the greatest increase in the less stable OM fractions (humic and fulvic acids). To obtain a better soil cover, and improve soil physical quality (low bulk density, high total porosity) and higher soybean yield, millet sowing is recommended in the second and third date with harvest only after the first flowering, and always maintaining the millet residue on the soil surface.
\end{abstract}

Index terms: bulk density, humic substances, no-tillage, Pennisetum glaucum, total porosity.

\section{INTRODUÇÃO}

O sistema plantio direto (SPD) tem sido uma das melhores opções para manutenção da sustentabilidade dos recursos naturais e utilização agrícola dos solos tropicais, onde o acúmulo de matéria orgânica ao longo do perfil e, por conseguinte, de $\mathrm{C}$ orgânico normalmente ocorre em velocidade bem menor do que em regiões de clima temperado (Dechen et al., 1981; Derpsch et al. 1986).
Por apresentar benefício ambiental (diminuição do deflúvio, principalmente de sedimentos) e econômico (amortização do custo de produção devido à economia de combustíveis fósseis), é possível que o SPD seja a contribuição mais importante que a agricultura está proporcionando em termos de adequação e validação de tecnologia; uma vez que causa menores perdas de solo (Wiethölter et al., 1998), o SPD é denominado um sistema de manejo de solo com caráter conservacionista. 
Neste sistema, a cultura da soja vem sendo bastante empregada, a qual tem grande importância econômica como uma das commodities brasileiras que contribuem para alavancar o crescimento da agricultura no País. Todavia, é necessário que medidas conservacionistas e que outras práticas de manejo da cultura sejam bem executadas. Parte da resolução de alguns problemas é dependente do plano de rotação e, ou, sucessão de culturas.

A associação de sistemas de sucessão de culturas com grande aporte de resíduos pode favorecer o acúmulo de grande quantidade de C orgânico (Lal, 2004). Esse tipo de manejo é um importante dreno de $\mathrm{CO}_{2}$ da atmosfera, no que se refere à mitigação do efeito estufa. Nesse raciocínio, torna-se relevante a participação do milheto, tendo em vista a utilização da soja - cultura de grande importância econômica no esquema de sucessão de culturas.

A introdução de culturas de cobertura com resistência a déficit hídrico, como o milheto e o sorgo, entre outras plantas de cobertura, é viável, pois propicia a manutenção de resíduos culturais, além de diminuir a amplitude térmica e conservar melhor a umidade do solo. Esse é um fator determinante na redução da erosão hídrica, pois a cobertura dissipa a energia cinética das gotas da chuva exatamente na superfície do solo (Duley, 1939). A cobertura do solo justifica-se ainda como barreira física ao livre escoamento superficial, diminuindo a velocidade e, assim, sua capacidade erosiva e desagregadora, bem como o selamento superficial das partículas do solo (Lombardi Neto et al., 1988).

Devido às particularidades do sistema de manejo com semeadura direta na palha e às relações com a estabilização do sistema, o fracionamento da matéria orgânica permite inferir sua qualidade e seu potencial de acúmulo, tendo em vista a melhoria de alguns atributos físicos do solo.

A matéria orgânica é, em grande parte, responsável pela qualidade física dos solos, ou seja, interfere na formação de agregados estáveis, na relação adequada entre macro e microporos e na retenção de água, os quais, por sua vez, afetam direta, ou indiretamente, a produtividade da soja.

O sistema de semeadura direta é a opção mais adequada para reverter a situação de degradação que pode ser gerada pelo cultivo convencional. Desde que seja adotado de modo correto, apresenta vantagens sobre os sistemas que revolvem o solo, como diminuição da erosão e manutenção ou aumento dos teores de matéria orgânica (De Maria et al., 1999). Proporciona ainda redução dos custos de produção, já que é notória a maior economia de combustível, em razão da ausência das operações de preparo, permitindo melhor racionalização no uso de máquinas, implementos e equipamentos, possibilitando assim que as diferentes culturas sejam implantadas nas épocas indicadas (Brancalião, 2000).
O objetivo do presente trabalho foi verificar a influência de diferentes épocas de semeadura e manejos da fitomassa do milheto em alguns atributos físicos do solo, nas frações húmicas, na cobertura do solo e na produtividade da soja.

\section{MATERIAL E MÉTODOS}

O experimento foi realizado na Faculdade de Ciências Agronômicas - UNESP - campus de Botucatu/SP, em um Nitossolo Vermelho distroférrico textura muito argilosa (Embrapa, 1999).

O delineamento experimental utilizado foi o de blocos casualizados, em esquema de parcelas subdivididas, com quatro repetições. Os tratamentos foram compostos por parcelas, sendo representadas por três épocas de semeadura da cultura do milheto $\left(\mathrm{E}_{1}, \mathrm{E}_{2}\right.$ e $\mathrm{E}_{3}$ ), sendo: $\mathrm{E}_{1}: 29 / 4 / 2003 ; \mathrm{E}_{2}: 21 / 5 / 2003(22$ dias após a primeira época); $\mathrm{e}_{3}: 15 / 6 / 2003$ (46 dias após a primeira época). Em decorrência da escassez de chuva, baixa germinação e temperaturas baixas, foi feita uma ressemeadura em 22/8/2003, caracterizando-se praticamente como uma semeadura em que o milheto desenvolveu sua fase vegetativa na primavera.

As subparcelas foram representadas pelo manejo da ceifa da fitomassa: manejo $1\left(\mathrm{M}_{1}\right)$ - ceifa a cada florescimento e retirada da fitomassa; manejo $2\left(\mathrm{M}_{2}\right)$ - ceifa a cada florescimento e permanência da fitomassa; manejo $3\left(\mathrm{M}_{3}\right)$ - ceifa apenas no primeiro florescimento e retirada da fitomassa; manejo $4\left(\mathrm{M}_{4}\right)$ - ceifa apenas no primeiro florescimento e permanência da fitomassa; e manejo $5\left(\mathrm{M}_{5}\right)$ - livre crescimento, sem ceifar.

As coordenadas geográficas de referência são: latitude sul $22^{\circ} 49^{\prime} 31^{\prime}$ e longitude oeste $48^{\circ}$ 25 ' 37 ". A altitude média é de $750 \mathrm{~m}$ e a declividade, de $8 \%$. A análise química do solo anteriormente à instalação dos tratamentos na camada de $0-0,20 \mathrm{~m}$ constou de: $\mathrm{pH} \mathrm{CaCl} 2,4,9 ; \mathrm{MOS}, 32 \mathrm{~g} \mathrm{dm}^{-3}$; P resina, $55,3 \mathrm{~g} \mathrm{dm}^{-3} ; \mathrm{K}, 4,1 \mathrm{mmol}_{\mathrm{c}} \mathrm{dm}^{-3} ; \mathrm{Ca}, 30 \mathrm{mmol}_{\mathrm{c}} \mathrm{dm}^{-3}$; $\mathrm{Mg}, 20 \mathrm{mmol}_{\mathrm{c}} \mathrm{dm}^{-3}$; acidez potencial $(\mathrm{H}+\mathrm{Al})$, $50 \mathrm{mmol}_{\mathrm{c}} \mathrm{dm}^{-3}$; CTC, $101 \mathrm{mmol}_{\mathrm{c}} \mathrm{dm}^{-3}$; V, $55 \%$. A caracterização física, na mesma camada avaliada, mostrou: $240 \mathrm{~g} \mathrm{~kg}^{-1} ; 110 \mathrm{~g} \mathrm{~kg}^{-1} ; 650 \mathrm{~g} \mathrm{~kg}^{-1}$; $1,49 \mathrm{~kg} \mathrm{dm}^{-3} ; 2,96 \mathrm{~kg} \mathrm{dm}^{-3} ; \mathrm{e} 48,47 \mathrm{~m}^{3} \mathrm{~m}^{-3}$ para areia, silte, argila, densidade do solo, densidade de partículas e porosidade total, respectivamente.

Foi estabelecida a modalidade de sucessão de culturas envolvendo o milheto na safrinha, como cultura de outono-inverno, e a soja, no verão. A pluviosidade do período (abril de 2003 a abril de 2004) em que foram feitas as avaliações após os tratamentos serem mantidos por três anos está representada na figura 1. 


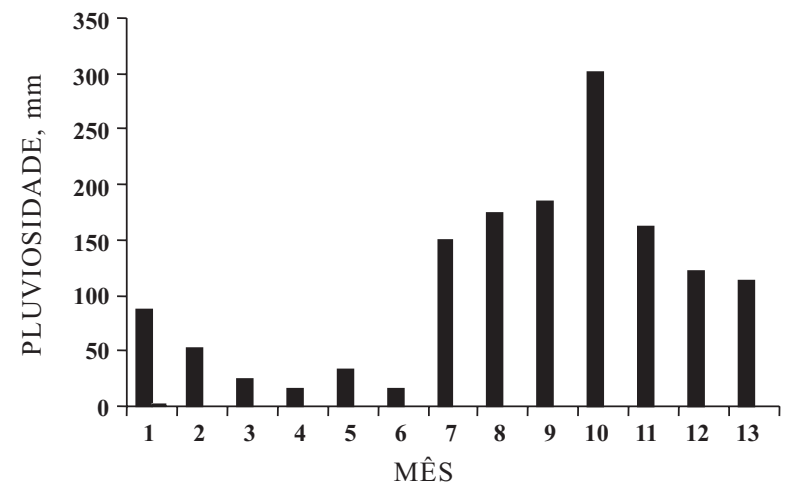

Figura1. Pluviosidade da área experimental no período de abril de 2003 (1) - abril de 2004 (13).

Para semeadura do milheto, utilizou-se o cultivar BN-2, no espaçamento de $0,17 \mathrm{~m}$, com $35 \mathrm{~kg} \mathrm{ha}^{-1} \mathrm{de}$ sementes, utilizando a fórmula 4-14-8 + 0,3\% de Zn, num total de $300 \mathrm{~kg} \mathrm{ha}^{-1}$. A cultura da soja foi semeada mecanicamente, utilizando-se a cultivar BRS-48, semiprecoce, no espaçamento de 0,45 m, empregando-se 30 sementes por metro, com população em torno de 400 mil plantas ha-1. A adubação de semeadura foi constituída por $300 \mathrm{~kg} \mathrm{ha}^{-1}$ da fórmula comercial 8-28-16+0,4 Zn.

Amostras com estrutura indeformada foram coletadas entre $0-0,05,0,05-0,10$ e $0,10-0,20 \mathrm{~m}$ de profundidade, para realização das análises físicas, a saber: densidade do solo e porosidade total (Embrapa, 1997). As amostras deformadas foram utilizadas para o carbono orgânico (Cantarella et al., 2001), em outubro de 2003.

A determinação da densidade do solo foi feita pelo método do anel volumétrico, totalizando 240 amostras, a qual foi realizada anteriormente à safra da soja, sendo os anéis pesados imediatamente após a coleta. A microporosidade do solo foi avaliada com a utilização da mesa de tensão, sendo os anéis saturados e submetidos à tensão de $60 \mathrm{~cm}$ de coluna de água. Considerando-se a diferença entre o peso saturado e a água retida nos poros, após o rompimento da coluna, determinou-se a macroporosidade.

Para extração da matéria orgânica e solubilização dos ácidos húmicos do solo, utilizou-se o método descrito por Kumada (1987), sendo as determinações realizadas de acordo com o método citado por Tatsukawa (1966), verificando-se o teor de $\mathrm{C}$ ligado à fração ácido húmico $(\mathrm{C}-\mathrm{AH})$ e o teor de $\mathrm{C}$ ligado à fração ácido fúlvico. $\mathrm{O} \mathrm{C}$ orgânico fora determinado pela oxidação com dicromato de potássio pelo método colorimétrico, e por diferença com os ácidos orgânicos obteve-se a fração insolúvel: humina.

\section{Soluções utilizadas}

- Solução NaOH: 0,1 mol L-1, 4 g de NaOH em 1 L.

- Solução para separação das frações húmicas: 0,18 $\mathrm{mol} \mathrm{L}^{-1} \mathrm{H}_{2} \mathrm{SO}_{4}: 10 \mathrm{~mL}$ de ácido sulfúrico em $1 \mathrm{~L}$.
- Solução MIXE: 0,2 mol L-1 $\mathrm{Na}_{2} \mathrm{SO}_{4}, 0,1 \mathrm{~mol} \mathrm{~L}-1$ $\mathrm{NaOH}$.

- Solução de dicromato de potássio + ácido sulfúrico concentrado: $3,175 \mathrm{~g}\left(\mathrm{~K}_{2} \mathrm{Cr}_{2} \mathrm{O}_{7}\right)$ em $500 \mathrm{~mL}$ de ácido sulfúrico concentrado.

- Solução de sacarose: (a) dissolveu-se 0,5 g de sucrose em água destilada em um balão volumétrico de $500 \mathrm{~mL}$; e (b) adicionou-se água, completando até o menisco para $1.000 \mathrm{mg} \mathrm{L}^{-1}$ de C. Pipetaram-se $5,10,25$ e $50 \mathrm{~mL}$ da solução-padrão de sacarose em balões volumétricos de $100 \mathrm{~mL}$ e, em seguida, completou com água até o menisco, compondo os extratos de $\mathrm{C}$, que permitiram preparar a curva: 50, 100, 250, $500 \mathrm{mg} \mathrm{L}^{-1}$ de C.

Adicionou-se $\mathrm{NaOH}$ às amostras de terra fina seca ao ar, que foram incubadas em banho-maria $\left(100^{\circ} \mathrm{C}\right)$ por $30 \mathrm{~min}$. Posteriormente ao resfriamento das amostras em gelo, adicionou-se sulfato de sódio, procedendo-se à centrifugação e posterior coleta do sobrenadante. Esse procedimento foi repetido por mais duas vezes, acrescentando-se solução MIXE entre uma centrifugação e outra, coletando-se o extrato. Para integralizar o extrato, adicionaram-se mais $10 \mathrm{~mL}$ da solução MIXE e imediatamente, utilizando-se de capela e proveta, colocou-se ácido sulfúrico concentrado. Agitou-se bem e deixou-se descansar por $5 \mathrm{~h}$.

As frações húmicas foram separadas por filtração, utilizando-se papel qualitativo Whatman número 6 , balão volumétrico e funil plástico. Os ácidos fúlvicos foram os primeiros a serem obtidos na filtração, e o volume foi completado com ácido sulfúrico $0,09 \mathrm{~mol} \mathrm{~L}^{-1}$, pois estes ácidos são solúveis em meio ácido. O filtro restante deste processo foi passado em um erlenmeyer, que foi solubilizado com a adição de $\mathrm{NaOH} \mathrm{0,1} \mathrm{mol} \mathrm{L}^{-1}$, agitando-se com bastão de vidro. Em seguida, foi realizada mais uma filtração (após todos os extratos apresentarem coloração uniforme) e o volume completado com a base forte, para completa uniformização do volume de amostras e conseqüente solubilização em meio básico.

A quantidade total de matéria seca do milheto para cada uma das três épocas e respectivos manejos e a produtividade da soja foram avaliadas, bem como a relação percentual entre solo coberto e descoberto, por meio de fotos digitalizadas da cultura do milheto, empregando-se o programa SIARCS (Jorge \& Crestana, 1996).

O estudo de todas as variáveis obtidas constou da análise de variância dos dados originais e aplicação do teste t de Student (LSD) para comparar as médias obtidas ( $\mathrm{p}<5 \%$ ). O nível de significância para o teste $\mathrm{F}$ foi de 5 e $1 \%$, respectivamente (Gomes, 1991).

\section{RESULTADOS E DISCUSSÃO}

A produtividade de matéria seca do milheto apresentou diferenças significativas em resposta a 
épocas de semeadura (Figura 2), destacando-se a $\mathrm{E}_{1}$, que proporcionou maior número de cortes no período de entressafra da soja. Para as épocas $\mathrm{E}_{2}$ e $\mathrm{E}_{3}$ as diferenças foram próximas, se for considerado que a $\mathrm{E}_{3}$ sofreu apenas um corte, enquanto para $\mathrm{E}_{2}$ houve estímulo ao florescimento, pelo fato de o milheto ser uma planta de dia curto (Ferraris \& Norman, 1976); para esta época de semeadura, o intervalo entre o corte e o florescimento diminui à medida que se aproxima $o$ início do inverno, tendo ela recebido dois cortes. Para o fator manejo não houve diferenças, todavia, para a interação, percebe-se que na primeira época apenas o $\mathrm{M}_{2}$ não revelou significativamente bom potencial produtivo de matéria seca.

Quanto à $\mathrm{E}_{1}$, foram superiores os manejos: $\mathrm{M}_{1}, \mathrm{M}_{3}$ $\mathrm{M}_{4}$ e $\mathrm{M}_{5}$. O $\mathrm{M}_{3}$ se mostrou eficiente nas $\mathrm{E}_{2}$ e $\mathrm{E}_{1}$, e o $\mathrm{M}_{2}$ igualou-se, proporcionando quantidade razoável de matéria seca ao longo do ano na $\mathrm{E}_{3}$; entretanto, na $\mathrm{E}_{2}$, o $\mathrm{M}_{2}$ permaneceu em situação intermediária, diferindo em $\mathrm{E}_{1}$ e não diferindo em $\mathrm{E}_{3}$. Para $\mathrm{E}_{3}$, devido à semeadura mais tardia, os tratamentos foram uniformizados e não diferiram entre si. Lançanova (1991) obteve resultados semelhantes manejando a fitomassa da cultura da aveia, ou seja, maior produção de fitomassa em corte único, comparado aos cortes sucessivos. Pode-se inferir que a planta expressou todo o seu potencial logo no primeiro corte; os cortes sucessivos suprimiram a rebrota da planta, devido ao dano causado a alguns de seus perfilhos.

Para Sodré Filho et al. (2004), em sistema plantio direto, o milheto resultou em 7 t ha-1 de matéria seca - marca inferior a de todos os tratamentos estudados.
Possivelmente esse fato pode ser atribuído à maior luminosidade da região do cerrado, enquanto na região de Botucatu a maior somatória de horas de escuro fez com que o período da semeadura até o florescimento fosse mais curto, possibilitando maior número de cortes e, conseqüentemente, maior produção de fitomassa do milheto. Embora a $\mathrm{E}_{1}$ tenha produzido maior quantidade de matéria seca, apresentou menor percentagem de cobertura do solo, pois a palhada tem boa degradabilidade.

O COT foi maior na primeira época, não havendo diferença entre a $E_{2}$ e $E_{3}$, e sim entre $E_{3}$ e $E_{1}$, nas camadas de 0-0,05 e 0,05-0,10 m. Entre 0,05 e 0,10 m (Figura 2), o $\mathrm{M}_{3}$ revelou-se com maior $\mathrm{C}$ orgânico total (COT). Ayanaba (1986) verificou patamares de produção de matéria seca de milheto próximos ao do sorgo, em torno de 7-8 t ha ${ }^{-1}$, o que conferiu, embora não significativamente, maior contribuição de $\mathrm{C}$ ao solo, por parte do sorgo. Entretanto, Reeves et al. (1995), comparando culturas de outono-inverno em sucessão com a soja e tremoço, observaram resultados de menor ganho de matéria seca por parte do tremoçobranco e maior por parte da soja em sucessão com o milheto.

A quantidade de C orgânico efetivamente adicionada ao solo dependeu principalmente da quantidade de resíduos adicionada e da facilidade de decomposição desses resíduos. Dessa forma, há dependência do manejo executado (rotação/sucessão) nas culturas, além da adição de matéria seca da parte aérea e da cobertura morta, revelando valores proporcionais de C orgânico (Figura 3). Os aportes de

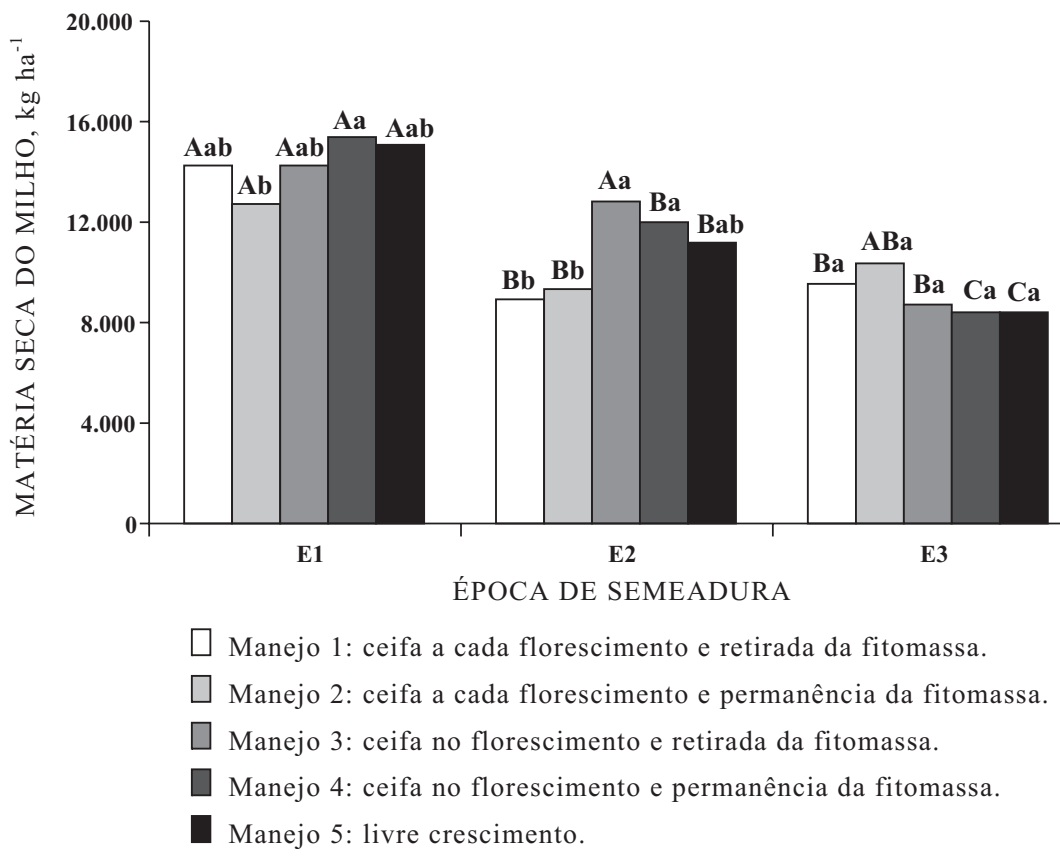

Figura 2. Quantidade total de matéria seca produzida pelo milheto em função de três épocas de semeadura $\left(E_{1}: 29 / 04 ; E_{2}: 21 / 05 ; E_{3}: 15 / 06\right)$ e do manejo da fitomassa (letras iguais, maiúsculas para época e minúsculas para manejo, não diferem entre si pelo teste LSD a $5 \%$ ). 
C em solos tropicais geralmente ocorrem superficialmente. Esse aporte é influenciado pela melhor distribuição de chuvas, correta manutenção da cobertura do solo e correto manejo em SPD. Nesse sentido, admite-se que em regiões de inverno seco o estudo de épocas é muito importante para relacionar o tempo de decomposição, a estabilização e a contínua mineralização da matéria orgânica do solo.

Obtiveram-se diferenças para o $\mathrm{E}_{1} \mathrm{M}_{3}$ na camada de $0,05-0,10 \mathrm{~m}$, sendo superior a $\mathrm{E}_{2}$, e essa época, por sua vez, com maior incremento no teor de COT do que em $\mathrm{E}_{3}$ (Figura 4). Ressalta-se também na camada de $0-0,05 \mathrm{~m}$ maior aporte de $\mathrm{C}$ com a interação do $\mathrm{E}_{2} \mathrm{M}_{4}$, sendo significativamente superior apenas em relação ao manejo com cortes sucessivos e retirada $\left(\mathrm{M}_{1}\right)$. Não houve diferença significativa entre os manejos para COT na $\mathrm{E}_{2}$ o que pode ser atribuído à maior percentagem de solo coberto, uniformizando os manejos da fitomassa.

Ceretta et al. (1994), trabalhando com culturas de inverno, obtiveram resultados com $\mathrm{C}$ orgânico da ordem de $11 \mathrm{~g} \mathrm{~kg}^{-1}$ e valores consideráveis de cobertura do solo - fato esse inerente à condição ótima de distribuição de chuvas da região. Amado et al. (1987), estudando um método de determinação de cobertura do solo, obtiveram maiores valores de COT mesmo com menor percentagem de solo coberto, o que certamente foi dependente do fato de a estação invernal

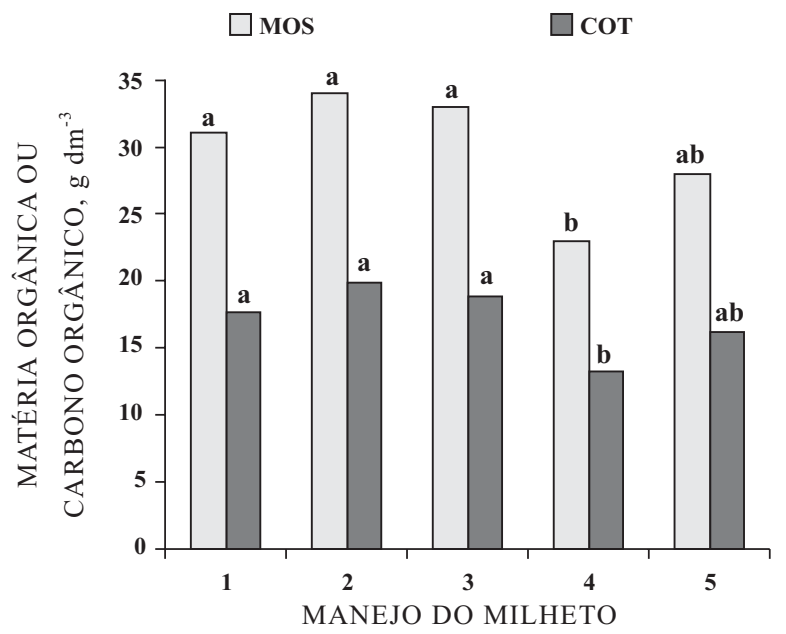

Figura 3. Teor de matéria orgânica do solo (MOS) ou carbono orgânico (COT) para os sistemas de manejo na época de semeadura $E_{1}$ na camada de 0-0,05 m (letras iguais não diferem entre si pelo teste LSD a $5 \%$ ). Manejo 1: ceifa a cada florescimento e retirada da fitomassa; Manejo 2: ceifa a cada florescimento e permanência da fitomassa; Manejo 3: ceifa apenas no primeiro florescimento e retirada da fitomassa; Manejo 4: ceifa apenas no primeiro florescimento $e$ permanência da fitomassa; Manejo 5: livre crescimento, sem ceifar.

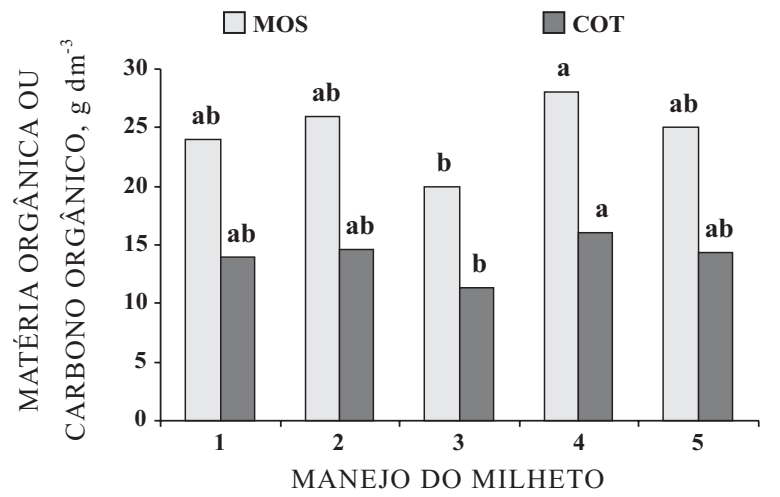

Figura 4. Teor de matéria orgânica do solo (MOS) ou carbono orgânico (COT) para os sistemas de manejo na época de semeadura $\mathrm{E}_{3}$ na camada de 0-0,05 m (letras iguais não diferem entre si pelo teste LSD a $5 \%$ ). Manejo 1: ceifa a cada florescimento e retirada da fitomassa; Manejo 2: ceifa a cada florescimento e permanência da fitomassa; Manejo 3: ceifa apenas no primeiro florescimento e retirada da fitomassa; Manejo 4: ceifa apenas no primeiro florescimento e permanência da fitomassa; Manejo 5: livre crescimento, sem ceifar.

ser chuvosa. No presente trabalho, onde o inverno é seco, a contribuição da cobertura do solo é maior.

Para época de semeadura, todas as frações húmicas diferiram em ambas as camadas, enquanto para manejo observou-se diferença na camada de 0,05-0,10 m (Quadro 1). As frações ácido húmico (C-AH) e ácido fúlvico (C-AF) foram maiores no tratamento $\mathrm{E}_{1} \mathrm{M}_{2}$ (com ceifa a cada florescimento e cobertura).

Ceretta et al. (1997), analisando o acúmulo da fração humina em três profundidades, com sucessão de culturas em SPD, estabelecidas há seis anos, constataram incrementos na quantidade de C armazenado, principalmente nas frações ácido húmico (C-AH) e ácido fúlvico (C-AF), e predomínio da humina (C-HU), além do fato de que os teores de C-AH variaram no intervalo de 1,5-3,0 $\mathrm{g} \mathrm{kg}^{-1}$; quando o sistema consistia na utilização de gramíneas, o aporte desta fração foi maior. Os resultados da fração humina também ocorreram em Botucatu, com milheto em sucessão à soja.

Os teores obtidos para as frações húmicas e a maior proporção da fração C-AF em relação à húmica concordam com os resultados de Gonçalves (2003), verificados para condições de clima tropical, com milho safrinha e adição de calagem em superfície.

Quanto à fração humina (C-HU), houve diferença para época nas duas camadas amostradas e diferença significativa de 0,05-0,10 m para manejo e interação; para a fração C-HU também houve diferença entre épocas de 0-0,05 e 0,05-0,10 m (Quadro 1). Na 
Quadro 1. Análise de variância (teste F) das frações húmicas em função da época e do manejo do milheto

\begin{tabular}{|c|c|c|c|c|c|c|}
\hline \multirow{3}{*}{ Causas de variação } & \multicolumn{6}{|c|}{ Valores do teste F } \\
\hline & \multicolumn{2}{|c|}{ C-AH } & \multicolumn{2}{|c|}{ C-AF } & \multicolumn{2}{|c|}{ C-HU } \\
\hline & $0,0-0,05 \mathrm{~m}$ & $0,05-0,10 \mathrm{~m}$ & $0,0-0,05 \mathrm{~m}$ & $0,05-0,10 \mathrm{~m}$ & $0,0-0,05 \mathrm{~m}$ & $0,05-0,10 \mathrm{~m}$ \\
\hline Época (E) & $23,03^{* *}$ & $11,15^{* *}$ & $17,75^{* *}$ & $9,66^{* *}$ & $2,697^{*}$ & $11,085 * *$ \\
\hline Manejo (M) & $1,50^{\mathrm{ns}}$ & $3,32^{*}$ & $1,70^{\mathrm{ns}}$ & $3,37 *$ & $0,303^{\mathrm{ns}}$ & $3,445^{*}$ \\
\hline $\mathrm{E} \times \mathrm{M}$ & $2,94^{*}$ & $2,31^{*}$ & $2,33^{*}$ & $1,70^{\mathrm{ns}}$ & $1,687^{\mathrm{ns}}$ & $2,187^{*}$ \\
\hline CV parcela $(\%)$ & 13,43 & 12,03 & 15,01 & 13,38 & 11,05 & 10,02 \\
\hline $\mathrm{CV}_{\text {subparcela }}(\%)$ & 11,02 & 12,03 & 16,02 & 12,03 & 11,02 & 10,01 \\
\hline DMS (E) & 0,13 & 0,11 & 0,21 & 0,31 & 1,71 & 0,79 \\
\hline DMS (M) & 0,17 & 0,14 & 0,27 & 0,38 & 2,21 & 1,02 \\
\hline
\end{tabular}

Carbono ligado aos ácidos húmicos (C-AH); carbono ligado aos ácidos fúlvicos (C-AF) e carbono ligado à fração humina (C-HU); ns: não-significativo, ${ }^{* *}$ significativo a $1 \%$ e *significativo a $5 \%$.

camada de $0-0,05 \mathrm{~m}$, a $\mathrm{E}_{1}$ foi significativamente superior à época mais tardia $\left(\mathrm{E}_{3}\right)$. Já na camada de 0,05-0,10 $\mathrm{m}$ a diferença significativa de $\mathrm{E}_{1}$ foi em relação a $\mathrm{E}_{2}$ e $\mathrm{E}_{3}$. Não houve diferença para o fator manejo na camada de 0-0,05 $\mathrm{m}$, embora na de 0,05-0,10 $\mathrm{m}$ tenha havido diferença, apontando maiores valores para $\mathrm{M}_{3}$ em relação a todos os outros manejos. Verificou-se que o $\mathrm{M}_{3}$ foi significativamente maior na $E_{1}$ e que também o $E_{1} M_{3}$ foi superior significativamente ao $\mathrm{E}_{2} \mathrm{M}_{3}$, e este, por sua vez, em relação a $\mathrm{E}_{3} \mathrm{M}_{3}$.

Para esta fração mais recalcitrante do solo, a humina (Stevenson, 1994), não ocorreram diferenças entre os sistemas de manejo da fitomassa do milheto

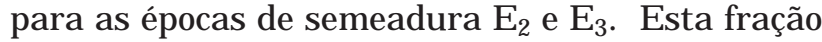
orgânica é a mais estável e menos sujeita a mudanças. Martim et al. (1982), ao avaliarem a perda acumulativa de matéria orgânica em solos de carga variável, ressaltaram a importância de solos de carga dependentes de $\mathrm{pH}$, pois a fração mineral está intimamente ligada, e a humina é a fração mais estável, que dificulta a perda do estoque de $\mathrm{C}$ dos solos.

Souza \& Melo (2003), estudando diferentes sistemas de produção envolvendo soja e milho, também obtiveram resultados que favoreceram a elevação dos teores de $\mathrm{C}$ na fração humina superficialmente. Conforme comentam Tate III (1987) e Brady (1989), o maior valor de $\mathrm{C}$ na forma de humina implica, em última instância, maior retenção de água, além da melhoria na qualidade física e química do solo, fatores de extrema importância quando se estuda o desenvolvimento de sistemas sustentáveis de produção agrícola. Santos (2000) também encontrou resultados similares com a cultura do milho.

Na camada de 0-0,05 m (Quadro 2), quanto ao fator época, destacou-se a $\mathrm{E}_{2}$, com menores valores de densidade do solo(Ds). Todavia, logo abaixo, na camada de 0,05-0,10 m, verificou-se significância estatística tanto para época como para manejo; o único a apresentar valores acima de $1,40 \mathrm{~kg} \mathrm{dm}^{-3}$ foi o $\mathrm{M}_{1}$, diferindo significativamente dos demais manejos, evidenciando a importância da cobertura sobre o solo. Assim, pode-se atribuir o comportamento com maior adensamento para $M_{1}$, pois as ceifas foram efetuadas e a fitomassa retirada para todos os períodos de florescimento, fazendo com que o solo ficasse por mais tempo descoberto do que no $\mathrm{M}_{3}$; embora este também não tenha palha, a maior altura das plantas de $\mathrm{M}_{3}$, em função do tipo do manejo do milheto, pode ter contribuído para essa diferenciação, o que, certamente, protegeu mais o solo, diminuindo o impacto da energia cinética das gotas de chuva (Siqueira et al., 1997; Brancalião, 2002). A densidade do solo e a microporosidade mostraram valores maiores, e a porosidade total e a macroporosidade, menores, na $\mathrm{E}_{3}$.

A melhor cobertura do solo proporcionada pela $\mathrm{E}_{2}$ contribuiu para melhor condição de estrutura do solo, revelando menores resultados; no desdobramento da interação, esta fração não diferiu de $\mathrm{E}_{2} \mathrm{M}_{3}$. Os resultados médios do ensaio são semelhantes aos de Albuquerque et al. (2001), que verificaram maior densidade do solo em subsuperfície no plantio direto; embora não tenham sido comparadas as camadas, o comportamento se assemelha em se tratando de um Nitossolo Vermelho. Para Oades et al. (1984), o maior conteúdo de ácido fúlvico pode ter proporcionado incremento significativo da densidade do solo (DS).

Os resultados do presente trabalho aproximam-se daqueles dos trabalhos de Albuquerque et al. (1995) e Bertol et al. (2000) para a Ds de 0-0,20 m. Nas camadas superficiais, Eltz et al. (1989) obtiveram resultados de Ds superiores a $1,10 \mathrm{~kg} \mathrm{dm}^{-3} \mathrm{em}$ sistema semeadura 
Quadro 2. Atributos físicos do Nitossolo Vermelho avaliados em outubro de 2003

\begin{tabular}{lllllll}
\hline & \multicolumn{4}{c}{ Camada } \\
\cline { 2 - 6 } Tratamento & $0-0,05 \mathrm{~m}$ & $0,05-0,10 \mathrm{~m}$ & $0,10-0,20 \mathrm{~m}$ & $0-0,05 \mathrm{~m}$ & $0,05-0,10 \mathrm{~m}$ & $0,10-0,20 \mathrm{~m}$ \\
\hline
\end{tabular}

Densidade do solo $\left(\mathrm{kg} \mathrm{dm}^{-3}\right)$

Macroporosidade $\left(\mathrm{m}^{3} \mathrm{~m}^{-3}\right)$

\begin{tabular}{|c|c|c|c|c|c|c|}
\hline $\mathrm{E}_{1}$ & $1,37 \mathrm{~A}$ & $1,37 \mathrm{~B}$ & $1,48 \mathrm{~B}$ & $0,14 \mathrm{~A}$ & $0,10 \mathrm{~A}$ & 0,10 \\
\hline $\mathrm{E}_{2}$ & $1,26 \mathrm{~A}$ & $1,28 \mathrm{C}$ & $1,37 \mathrm{C}$ & $0,12 \mathrm{~A}$ & $0,11 \mathrm{~A}$ & 0,13 \\
\hline $\mathrm{E}_{3}$ & $1,39 \mathrm{~A}$ & $1,45 \mathrm{~A}$ & $1,56 \mathrm{~A}$ & $0,07 \mathrm{~B}$ & $0,07 \mathrm{~B}$ & 0,10 \\
\hline $\mathrm{M}_{1}$ & $1,32 \mathrm{a}$ & $1,43 \mathrm{a}$ & $1,44 \mathrm{a}$ & $0,11 \mathrm{ab}$ & $0,07 \mathrm{~b}$ & 0,09 \\
\hline $\mathrm{M}_{2}$ & $1,33 \mathrm{a}$ & $1,36 \mathrm{~b}$ & $1,51 \mathrm{a}$ & $0,09 \mathrm{~b}$ & $0,09 \mathrm{ab}$ & 0,07 \\
\hline $\mathrm{M}_{3}$ & $1,35 \mathrm{a}$ & $1,37 \mathrm{~b}$ & $1,48 \mathrm{a}$ & $0,10 \mathrm{ab}$ & $0,07 \mathrm{~b}$ & 0,12 \\
\hline $\mathrm{M}_{4}$ & $1,35 \mathrm{a}$ & $1,32 \mathrm{~b}$ & $1,46 \mathrm{a}$ & $0,13 \mathrm{a}$ & $0,12 \mathrm{a}$ & 0,13 \\
\hline $\mathrm{M}_{5}$ & $1,35 \mathrm{a}$ & $1,35 \mathrm{~b}$ & $1,46 \mathrm{a}$ & $0,09 b$ & $0,10 \mathrm{ab}$ & 0,11 \\
\hline $\mathrm{CV}_{\text {parcela }}(\%)$ & 6,69 & 4,89 & 5,03 & 36,48 & 54,36 & 27,53 \\
\hline $\mathrm{CV}_{\text {subparcela }}(\%)$ & 5,59 & 3,43 & 2,65 & 26,54 & 24,52 & 16,52 \\
\hline & \multicolumn{3}{|c|}{ Porosidade total $\left(\mathrm{m}^{3} \mathrm{~m}^{-3}\right)$} & \multicolumn{3}{|c|}{ Microporosidade $\left(\mathrm{m}^{3} \mathrm{~m}^{-3}\right)$} \\
\hline $\mathrm{E}_{1}$ & $0,45 \mathrm{~A}$ & $0,42 \mathrm{~A}$ & $0,44 \mathrm{~A}$ & 0,31 & 0,30 & 0,33 \\
\hline $\mathrm{E}_{2}$ & $0,45 \mathrm{~A}$ & $0,43 \mathrm{~A}$ & $0,47 \mathrm{~A}$ & 0,33 & 0,32 & 0,34 \\
\hline E3 & $0,41 \mathrm{~B}$ & $0,40 \mathrm{~B}$ & $0,41 \mathrm{~A}$ & 0,35 & 0,34 & 0,32 \\
\hline $\mathrm{M}_{1}$ & $0,43 \mathrm{a}$ & $0,41 \mathrm{a}$ & $0,42 \mathrm{a}$ & 0,32 & 0,34 & 0,33 \\
\hline $\mathrm{M}_{2}$ & $0,44 \mathrm{a}$ & $0,43 \mathrm{a}$ & $0,41 \mathrm{a}$ & 0,35 & 0,33 & 0,33 \\
\hline $\mathrm{M}_{3}$ & $0,44 \mathrm{a}$ & $0,41 \mathrm{a}$ & $0,45 \mathrm{a}$ & 0,34 & 0,34 & 0,32 \\
\hline $\mathrm{M}_{4}$ & $0,43 \mathrm{a}$ & $0,42 \mathrm{a}$ & $0,47 \mathrm{a}$ & 0,30 & 0,27 & 0,34 \\
\hline $\mathrm{M}_{5}$ & $0,44 \mathrm{a}$ & $0,41 \mathrm{a}$ & $0,46 \mathrm{a}$ & 0,35 & 0,31 & 0,34 \\
\hline $\mathrm{CV}_{\text {parcela }}(\%)$ & 7,85 & 6,56 & 27,53 & 10,39 & 19,90 & 7,64 \\
\hline $\mathrm{CV}_{\text {subparcela }}(\%)$ & 6,85 & 5,32 & 25,32 & 12,36 & 18,25 & 6,32 \\
\hline
\end{tabular}

Médias seguidas de mesmas letras, maiúsculas (Época) e minúsculas (Manejo) nas colunas, não diferem entre si pelo teste tLSD-Student $(\mathrm{P}<0,05)$, números sem letras não diferem entre si. Manejo - 1: ceifa a cada florescimento e retirada da fitomassa; 2: ceifa a cada florescimento e permanência da fitomassa; 3: ceifa no florescimento e retirada da fitomassa; 4: ceifa no florescimento e permanência da fitomassa; 5: livre crescimento, sem ceifar. Épocas 1, 2 e 3: primeira, segunda e terceira épocas de semeadura do milheto, respectivamente.

direta, com oito anos no sistema, ao passo que Costa et al. (2003) encontraram valores menores, entre 0,9 e $1,0 \mathrm{~kg} \mathrm{dm}^{-3}$ - aspecto que revela maior estabilização do sistema após esse tempo de adoção para essa propriedade física. Há relatos de que a compactação do solo limita a altura final de plantas sensivelmente em semeadura direta (Braga et al., 2005).

$\mathrm{O} \mathrm{M}_{3}$ apresentou maior porosidade total que o $\mathrm{M}_{1}$. Para o $\mathrm{M}_{2}$ na $\mathrm{E}_{1}$, com cobertura deixada sobre o solo e cortes sucessivos, evidenciou-se o efeito proporcionado com a contínua adição de fitomassa em cobertura sobre o solo. O maior valor de porosidade total do solo, da interação $\mathrm{E}_{1} \mathrm{M}_{2}$, pode ser associado à antecipação da semeadura com solo coberto com adição contínua da fitomassa.

Quanto à macroporosidade (Quadro 2), que representa a capacidade de aeração do solo, ou seja, o componente da porosidade total do solo que expressa o volume de poros maiores que contribuem para oxigenação radicular, as duas primeiras épocas de semeadura resultaram em maiores valores de macroporosidade nas camadas mais superficiais do solo. Isso pode confirmar a influência do tempo em que o solo ficou com cobertura, refletindo na melhoria da sua qualidade física. Na camada de 0-0,05 m, na $\mathrm{E}_{3}$ e para os manejos $\mathrm{M}_{2}$ e $\mathrm{M}_{5}$, os resultados foram inferiores ao mínimo considerado restritivo ao crescimento e desenvolvimento das plantas, ou seja, $0,10 \mathrm{dm}^{3} \mathrm{dm}^{-3}$ (Vomocil \& Flocker, 1966), embora esse valor-limite dependa do tipo de planta e do nível da atividade biológica do solo (Gupta et al., 1989), entre outros fatores. Reduções na macroporosidade em solos sob semeadura direta também foram observadas por Tormena et al. (1998). No tocante à microporosidade, verificou-se significância estatística 
$(\mathrm{p}<0,05)$ nas camadas de $0-0,05$ e $0,05-0,10 \mathrm{~m}$ para época e manejo.

A percentagem de cobertura do solo resultou em diferenças significativas entre as épocas de semeadura do milheto (Quadro 3), destacando-se $\mathrm{E}_{2} \mathrm{e}_{3}$. $\mathrm{O} \mathrm{M}_{4}$, com corte no único florescimento e permanência, diferiu significativamente dos demais, e o $\mathrm{M}_{1}$ foi o que proporcionou significativamente menor percentagem de cobertura na superfície.

O milheto, em sucessão com a soja, proporcionou esses resultados pelo fato de ter apresentado melhor crescimento nas épocas $\mathrm{E}_{2}$ e $\mathrm{E}_{3}$, pois, embora semeadas tardiamente, proporcionaram melhor cobertura do solo. $\mathrm{A} \mathrm{E}_{2}$ foi mais eficiente na cobertura do solo, em razão da precipitação que ocorreu na rebrota após o primeiro corte.

Lemos et al. (2003) verificaram, na sucessão milheto-soja, maior população de plantas de soja no $\mathrm{M}_{4}$ e na $\mathrm{E}_{1}$, onde também foi efetuado o corte apenas no primeiro florescimento com permanência da palha. É notória a relação existente entre cobertura do solo, produção de matéria seca e produtividade da soja.

$\mathrm{OM}_{4}$ na $\mathrm{E}_{3}$ teve produção significativamente igual à do $\mathrm{E}_{2} \mathrm{M}_{4}$, devido à quantidade de fitomassa. Embora tenha recebido apenas um corte, o aumento foi crescente do comprimento do dia nesta época de semeadura $\left(\mathrm{E}_{3}\right)$, já que a partir do dia $24 / 6$ (solstício de inverno no hemisfério sul) o comprimento do dia é crescente.

O milheto, por possuir sensibilidade ao fotoperíodo de outono-inverno (Ferraris \& Norman, 1976), teve sua fase vegetativa mais desenvolvida no mês de agosto e até $50 \%$ da emissão de panículas em meados de outubro, caracterizando-se, na $\mathrm{E}_{3}$, como planta de cobertura na primavera. A cobertura do solo proporcionada pela fitomassa do milheto foi maior nas épocas $\mathrm{E}_{2}$ e no $\mathrm{M}_{4}$, com único corte e permanência da fitomassa (Quadro 3).

De acordo com os resultados de macro e microporosidade, é necessário inferir que a maior contribuição para produtividade da soja foi por parte da macroporosidade, uma vez que é possível identificar melhores condições de porosidade de aeração na camada de $0-0,05 \mathrm{~m}$. Esse resultado corrobora os de Siqueira et al. (1997) e se aproxima da correlação positiva entre macroporosidade superficial do solo e produtividade de grãos de soja, devido à maior aeração proporcionada, o que provavelmente também favoreceu a fixação biológica de $\mathrm{N}_{2}$ (Siqueira et al., 1997).

Derpsch et al. (1986) verificaram maior densidade do solo em semeadura direta, trabalhando com solo argiloso, porém os rendimentos de soja foram satisfatórios, não diferindo do tratamento com menores valores de compactação.

A maior quantidade de fitomassa do milheto é importante para a cultura subseqüente, ou seja, para a soja; Lemos et al. (2003) constataram que época e manejo influenciaram a cultura da soja. Constataram também que, quanto maior a quantidade de fitomassa em cobertura, ou seja, da palha restante sobre o solo, maior a população final de plantas (stand) de soja. Resultados semelhantes foram descritos por Cordeiro \& Souza (1999), caracterizando a superioridade do milheto perante a vegetação espontânea em SPD, levando ao melhor estabelecimento da cultura posteriormente semeada.

Vale ressaltar que a última época do ano agrícola de 1999, segundo Lemos et al. (2003), aproximou-se da $E_{1}$ na sucessão milheto-soja para o ano de 2003, no presente estudo. A observação da pluviosidade é

Quadro 3. Percentagem de cobertura do solo pelo milheto e produtividade da soja em diferentes épocas de semeadura e manejos da fitomassa do milheto

\begin{tabular}{|c|c|c|c|c|c|c|c|c|}
\hline \multirow{2}{*}{$\begin{array}{l}\text { Manejo da } \\
\text { fitomassa }\end{array}$} & \multicolumn{4}{|c|}{ Cobertura do solo pelo milheto } & \multicolumn{4}{|c|}{ Produtividade da soja } \\
\hline & Época 1 & Época 2 & Época 3 & Média & Época 1 & Época 2 & Época 3 & Média \\
\hline & \multicolumn{4}{|c|}{$\%$} & \multicolumn{4}{|c|}{$\mathrm{tha}^{-1}$} \\
\hline M1 & 60 & 60 & 60 & $60 \mathrm{c}$ & $3,22 \mathrm{Aa}$ & $3,17 \mathrm{Aa}$ & $3,23 \mathrm{Aa}$ & $3,21 \mathrm{a}$ \\
\hline $\mathrm{M} 2$ & 76 & 80 & 60 & $72 \mathrm{~b}$ & $2,96 \mathrm{Aa}$ & $2,88 \mathrm{Aa}$ & $3,22 \mathrm{Aa}$ & $3,02 \mathrm{a}$ \\
\hline M3 & 61 & 86 & 59 & $69 \mathrm{~b}$ & $3,14 \mathrm{Aa}$ & $3,14 \mathrm{Aa}$ & $3,12 \mathrm{Aa}$ & $3,13 \mathrm{a}$ \\
\hline M4 & 73 & 83 & 85 & $80 \mathrm{a}$ & $2,85 \mathrm{Ba}$ & $3,40 \mathrm{Aa}$ & $3,06 \mathrm{ABa}$ & $3,10 \mathrm{a}$ \\
\hline M5 & 72 & 73 & 73 & $73 \mathrm{~b}$ & $3,10 \mathrm{Aa}$ & $3,24 \mathrm{Aa}$ & $3,16 \mathrm{Aa}$ & $3,17 \mathrm{a}$ \\
\hline Média & $68 \mathrm{~B}$ & $76 \mathrm{~A}$ & $67 \mathrm{~B}$ & & $3,06 \mathrm{~A}$ & $3,16 \mathrm{~A}$ & $3,16 \mathrm{~A}$ & \\
\hline
\end{tabular}

Médias seguidas de mesmas letras, maiúsculas nas linhas e minúsculas nas colunas, não diferem entre si pelo teste LSD-Student $(\mathrm{p}<0,05)$. Manejo - 1: ceifa a cada florescimento e retirada da fitomassa; 2: ceifa a cada florescimento e permanência da fitomassa; 3: ceifa no florescimento e retirada da fitomassa; 4: ceifa no florescimento e permanência da fitomassa; 5: livre crescimento, sem ceifar. Épocas 1, 2 e 3: primeira, segunda e terceira épocas de semeadura do milheto, respectivamente. 
importante; Secco et al. (2004) também constataram um pico de precipitação ao longo do ciclo da soja no mês de janeiro, tal como verificado neste trabalho, sendo superior a $300 \mathrm{~mm}$ só neste mesmo mês. Esse período coincide exatamente com o pleno florescimento da cultura da soja, o que notoriamente refletiu em maior estabilidade na produção.

\section{CONCLUSÕES}

1. A produtividade de matéria seca do milheto decresceu na ordem $\mathrm{E}_{1}>\mathrm{E}_{2}>\mathrm{E}_{3}$.

2. A densidade do solo, a macroporosidade, a microporosidade e a porosidade total variaram com a época de semeadura do milheto.

3. A adição contínua de fitomassa com ceifa a cada florescimento e permanência da cobertura proporcionou maior incremento nas frações menos estáveis da matéria orgânica (ácido húmico e ácido fúlvico).

4. Recomenda-se, diante das condições edafoclimáticas estudadas, a semeadura do milheto na segunda e terceira épocas, ambas utilizando-se da permanência da fitomassa e corte apenas no primeiro florescimento, para obter melhor cobertura, qualidade física do solo (menor densidade do solo e maior porosidade total) e maior produtividade da soja.

\section{LITERATURA CITADA}

ALBUQUERQUE, J.A.; REINERT, D.J.; FIORIN, J.E.; RUEDELL, J.; PETRERE, C. \& FONTINELLI, F. Rotação de culturas e sistema de manejo do solo: Efeito sobre a forma da estrutura do solo ao final de sete anos. R. Bras. Ci. Solo, 19:115-119, 1995.

ALBUQUERQUE, J.A.; SANGOI, L. \& ENDER, M. Efeitos da integração lavoura-pecuária nas propriedades físicas do solo e características da cultura do milho. R. Bras. Ci. Solo, 25:717-723, 2001.

AMADO, T.J.C.; ALMEIDA, E.X.; DALLAGNOL, I. \& MATOS, A.T. Determinação da cobertura do solo por adubos verdes. Florianópolis, EMPASC, 1987.6p.

AYANABA, A. The value of mulches in the management of organic matter in tropical soils. In: COLÓQUIO REGIONAL SOBRE MATÉRIA ORGÂNICA DO SOLO, 1986, Piracicaba. Colóquio. Piracicaba, CENA, 1986. p.97103.

BERTOL, I.; SCHICK, J.; MASSARIOL, J.M.; REIS, E.F. \& DILY, L. Propriedades físicas de um Cambissolo Húmico álico afetadas pelo manejo do solo. R. Ci. Rural, 30:91-95, 2000 .
BRADY, N.C. Suprimento e assimilabilidade do fósforo e do potássio. In: BRADY, N.C. Natureza e propriedades dos solos. 7.ed. Rio de Janeiro, Freitas Bastos, 1989. p.373413.

BRAGA, F.V.A.; REINERT, D.J.; REICHERT, J.M.; LIMA, C.L.R.; SUZUKI, L.E.A.S. \& GUBIANI, P.I. Emergência de plântulas no desenvolvimento de soja e feijoeiro de um Argissolo Vermelho sob sistema de semeadura direta. In: CONGRESSO BRASILEIRO DE CIÊNCIA DO SOLO, 30., Recife,.2005. Anais. Recife, Sociedade Brasileira de Ciência do Solo, 2005. CD-ROM.

BRANCALIÃO, S. R.; MARTINS, M.I.E.G. \& ANDRIOLI, I. Avaliação econômica dos sistemas de semeadura direta e convencional na rotação sorgo/soja (Sorghum bicolor L./ Glycine $\max$ L.) na região de Ribeirão Preto (SP): estudo de caso.In: Reunião Brasileira de manejo e Conservação do Solo e da Água, 13., Ilhéus, 2000. Anais. Ilhéus, Sociedade Beasileira de Ciência do Solo, 2000. CD-ROM.

BRANCALIÃO, S.R. Efeito da fitomassa do milheto sobre as propriedades físicas e químicas de um Nitossolo Vermelho e na produtividade da soja cultivada em sistema de semeadura direta em Botucatu - SP. Botucatu, Universidade Estadual Paulista, 2002. 73p. (Tese de Mestrado)

CANTARELlA, H.; QUAGGIO, J.A. \& RAIJ, B.van. Determinação da matéria orgânica. In: RAIJ, B.van; ANDRADE, J.C.; CANTARELLA, H. \& QUAGGIO, J.A., eds. Análise química para avaliação da fertilidade de solos tropicais. Campinas, Instituto Agronômico, 2001. p.173180.

CERETTA C.A.; AITA, C.; BRAIDA, J.A.; PAVINATO A. \& SALET, R.L. Fornecimento de nitrogênio por leguminosas na primavera para o milho em sucessão nos sistemas de cultivo mínimo e convencional. R. Bras. Ci. Solo, 18:215-220, 1994.

CERETTA, C.A.; MARCOLAN, A.L.; DURGON, R. \& TISSOT, A.R. Acúmulo de carbono em humina, ácidos fúlvicos e húmicos em três profundidades de solo com sistema de cultura, sob plantio direto, durante 6 anos. In: ENCONTRO BRASILEIRO DE SUBSTÂNCIAS HÚMICAS, 2., São Carlos, 1997. Anais. São Carlos, Embrapa, 1997. p.136.

CORDEIRO, L.A.M. \& SOUZA, C.M. Características agronômicas da cultura da soja (cv.IAC-1) semeada sobre palha de diferentes espécies de cobertura morta em sistema plantio direto. In: CONGRESSO BRASILEIRO DE CIÊNCIA DO SOLO, 27., Brasília, 1999. Resumos Expandidos. Brasília, CPAC/Embrapa, Sociedade Brasileira de Ciência do Solo, 1999. CD-ROM.

COSTA, F.S.; ALBUQUERQUE, J.A.; BAYER, C.; FONTOURA, S.M.V. \& WOBETO, C. Propriedades físicas de um Latossolo Bruno afetadas pelos sistemas plantio direto e preparo convencional. R. Bras. Ci. Solo, 27:527$535,2003$.

DE MARIA, I.C.; MNABUDE, P.C. \& CASTRO, O.M. Long term tillage and crop rotation effects on soil chemical properties of a Rhodic Ferralsol in Southern Brazil. Soil Till. Res., 51:71-79, 1999. 
DECHEN, S.C.F.; LOMBARDI NETO, F. \& CASTRO, O.M. Gramíneas e leguminosas e seus restos culturais no controle da erosão em Latossolo Roxo. R. Bras. Ci. Solo, 5:133-137, 1981.

DERPSCH, R.; SIDIRAS, N. \& ROTH, C.H. Results of studies made from 1977 to 1984 to control erosion by cover crops and no-tillage techniques in Paraná, Brazil. Soil Till. Res., 8:253-263, 1986.

DULEY, F.L. Surface factors affecting the rate of intake of water by soils. Soil Sci. Soc. Am. Proc., 4:60-64, 1939.

ELTZ, F.L.P.; PEIXOTO, R.T.G. \& JASTER, F. Efeitos de sistema de preparo de solo nas propriedades físicas e químicas de um Latossolo Bruno álico. R. Bras. Ci. Solo, 13:259-267, 1989.

EMPRESA BRASILEIRA DE PESQUISA AGROPECUÁRIA EMBRAPA. Centro Nacional de Pesquisa de Solos. Sistema brasileiro de classificação de solos. Rio de Janeiro, 1999. 412p.

EMPRESA BRASILEIRA DE PESQUISA AGROPECUÁRIA - EMBRAPA. Manual de métodos de análises de solo. 2.ed. Rio de Janeiro, Ministério da Agricultura e do Abastecimento, 1997. 212p.

FERRARIS, R. \& NORMAN, M.J.T. Factors affecting the regrowth of Pennisetum americanum under frequent defoliation. Aust. J. Agric. Res., 27:365-371, 1976.

GOMES, F.P. Curso de estatística experimental. 13.ed. Piracicaba, Nobel, 1991. 468p.

GONÇALVES, J.R.P. Granulometria e doses de calcário na cultura do milho e em atributos químicos do solo, em sistemas convencional e direto. Botucatu, Universidade Estadual Paulista, 2003. 143p. (Tese de Doutorado)

GUPTA, S.C.; HADAS, A. \& SCHAFER, R.L. Modeling soil mechanical behavior during compaction. In: LARSON, W.E.; BLAKE, G.R.; ALLMARAS, R.R.; VOORHEES, W.B. \& GUPTA, S.C., eds. Mechanics and related process in structured agricultural soils. Dordrecht, Kluwer Academic Publishers, 1989. p.137-152. (NATO Applied Sciences, 172)

JORGE, L.A.C. \& CRESTANA, S. SIARCS 3.0: Nova ferramenta para análise de imagens aplicada à ciência do solo. In: CONGRESSO LATINO-AMERICANO DE CIÊNCIA DO SOLO, 13., Águas de Lindóia, 1996. Anais. Águas de Lindóia, Sociedade Brasileira de Ciência do Solo, 1996. CD-ROM.

KUMADA, N. Soil organic matter analysis method. Chemistry of soil organic matter. Tokio, Japan Scientific Societies Press, 1987. p.95-97.

LAL, R. Soil carbon sequestration to mitigate climate change. Geoderma, 123:1-22, 2004

LANÇANOVA, J.A.C. Limitação para produção de leite a pasto. In: IAPAR, org. Organização das Cooperativas do Paraná.. Curso de atualização em pastagens. Cascavel, 1991. v.1. p.263-266.
LEMOS, L.B.; NAKAGAWA, J.; CRUSCIOL, C.A.C; CHIGNOLI JÚNIOR, W. \& DA SILVA, T.R.B. Influência da época de semeadura e do manejo da parte aérea de milheto sobre a soja em sucessão em plantio direto. Bragantia, 62:405-415, 2003.

LOMBARDI NETO, F.; DE MARIA, I.C.; CASTRO, O.M.; DECHEN, S.C.F. \& VIEIRA, S.R. Efeito da quantidade de resíduos culturais do milho nas perdas de solo e água. R. Bras. Ci. Solo, 12:71-75, 1988.

MARTIN, J.P.; ZUNINI, H.; PEIRANO, P.; CAIOZZI, M. \& HAIDER, K. Decomposition of ${ }^{14} \mathrm{C}$-labelled lignins, model humic acid polymers, and fungal melanins in allophonic soil. Soil Biol. Biochem., 14:289-293, 1982.

OADES, J.M. Soil organic matter and structural stability: Mechanisms and implications for management. Plant Soil, 76:319-37, 1984.

REEVES, D.W.; WRIGHT, D.L.; MULLINS G.L. \& van SANTEN, E. Influence of pearl millet on performance of winter annual crops. In: NATIONAL GRAIN PEARL MILLET PRODUCTION, 1., 1995, Tifton. p.81-86.

SANTOS, J.R. Produção de grão, estabilidade de agregados e frações do fósforo e da matéria orgânica do solo em função do manejo e da aplicação de calcário, gesso e vinhaça. Botucatu, Universidade Estadual de São Paulo, 2000. (Tese de Doutorado)

SECCO, D.; REINERT, D.J.;. REICHERT, J.M. \& DA ROS, C.O. Produtividade da soja e propriedades físicas de um Latossolo submetido a sistemas de manejo e compactação. R. Bras. Ci. Solo, 28:797-894, 2004.

SIQUEIRA, J.O.; MOREIRA, F.M.S.; GRISI, B.M.; HUNGRIA, M. \& ARAUJO, R.S. Microrganismos e processos biológicos no solo: Perspectiva ambiental. Embrapa -SPI, Brasília. 1994. 142p.

SIQUEIRA, J.O.; MOREIRA, F.M.S.; GRISI, B.M.; HUNGRIA, M. \& ARAUJO, R.S. Microorganismos e processos biológicos do solo: Perspectiva ambiental. Brasília, Embrapa-SPI/CNPAF, 1997. 142p. (Documentos, 45)

SODRÉ FILHO, J.; CARDOSO, A.N.; CARMONA, R. \& DE CARVALHO, A.M. Fitomassa em cobertura do solo de culturas de sucessão ao milho na região do Cerrado. Pesq. Agropec. Bras., 39:237-234, 2004.

SOUZA, W.J.O. \& MELO, W.J. Matéria orgânica em um Latossolo submetido a diferentes sistemas de produção de milho. R. Bras. Ci. Solo, 27:1113-1120, 2003.

STEVENSON, F.J. Humus chemistry: Genesis, composition, reactions. 2.ed. New York, John Wiley \& Sons, 1994. 496p.

TATE III, R.L. Humic and acids: Formation and decomposition. In: TATE III, R.L., ed. Soil organic matter: Biological and ecological effects. New York, John Willey \& Sons, 1987. p.147-164.

TATSUKAWA, T. Determination of fulvic and humic acid by Tatsukawa's method. J. Soil Sci. Plant Nutr., 37:28-33, 1966.

TORMENA, C.A.; ROLOFF, G. \& SÁ, J.C.M. Propriedades físicas do solo sob plantio direto influenciadas por calagem, preparo inicial e tráfego. R. Bras. Ci. Solo, 22:301-309, 1998. 
VOMOCIL, J.A. \& FLOCKER, W.J. Effect of soil compaction on storage and movement of soil, air and water. Trans. Am. Soc. Agric. Eng., 4:242-246, 1966.
WIETHÖLTER, S.; BEM, J.R.; KOCHHAN, R.A. \& PÖTKER, D. Fósforo e potássio no sistema de plantio direto. In: NUERNBERG, N.J., ed. Conceitos e fundamentos do sistema de plantio direto. Lages, Sociedade Brasileira de Ciência do Solo/Núcleo Regional Sul, 1998. p.121-149. 